\title{
Estratégias de adubação nitrogenada, características morfogênicas e estruturais em pastos de Brachiaria decumbens diferidos por 95 dias
}

\author{
Nitrogen fertilization strategies, morphogenetic and structural \\ features in Brachiaria decumbens deferred for 95 days
}

\author{
Fábio Andrade Teixeira ${ }^{1 *}$; Aureliano José Vieira Pires ${ }^{1}$; \\ Fabiano Ferreira Silva ${ }^{1}$; Daniela Deitos Fries²; Claudia de Paula Rezende ${ }^{3}$; \\ Alexsandro Cotrim Pimentel Ribeiro Costa ${ }^{4}$; Thiago Cardoso Santos ${ }^{4}$; \\ Paulo Valter Nunes Nascimento ${ }^{1}$
}

\begin{abstract}
Resumo
O objetivo deste trabalho foi avaliar as características morfogênicas e estruturais de pastos de Brachiaria decumbens para determinar estratégias de adubação nitrogenada, mais adequadas para o pastejo diferido por um período de 95 dias. Foram estudadas quatro estratégias de adubação no início e no final do verão $\left(0-0,100-0,50-50,0-100 \mathrm{~kg} \cdot \mathrm{ha}^{-1}\right.$ de $\left.\mathrm{N}\right)$, respectivamente, com quatro repetições. As estratégias de 100 kg.ha ${ }^{-1}$ de N, aplicados no final do verão (0-100) seguidas da estratégia de parcelamento no início e final do verão (50-50) favoreceram maiores taxas de aparecimento de folhas, menores valores de filocrono. Maior taxa de alongamento foliar foi encontrada para estratégia $0-100$, resultando num aumento de $40 \%$ em relação aos pastos que não foram adubados. Entretanto, não houve efeito das estratégias de adubação sobre a taxa de alongamento de colmo, registrando-se média de $0,28 \mathrm{~cm} \cdot \mathrm{dia}^{-1}$. As estratégias 0-100 e 50-50 promoveram maior relação lâmina:colmo no estrato vertical A. Não foi verificado efeito em relação ao número de folhas totais e ao comprimento final da folha. No entanto, maiores comprimentos de colmos foram observados nos pastos com estratégia de adubação $0-100$, seguida da estratégia 50 50. A estratégia de aplicação de $100 \mathrm{~kg} \cdot \mathrm{ha}^{-1}$ no final do verão, seguida da estratégia de $50 \mathrm{~kg} \cdot \mathrm{ha}^{-1} \mathrm{de}$ $\mathrm{N}$ parcelado no início e final do verão, promovem maior influência sobre as variáveis morfogênicas e estruturais em pastos diferidos por 95 dias.
\end{abstract}

Palavras-chave: Filocrono, morfogênese, pasto diferido, uréia

\begin{abstract}
The aim this work was to evaluate the morphogenic and structural characteristics of Brachiaria decumbens pastures to determine the most suitable nitrogen fertilization strategies, for pastures deferred for a period of 95 days. Four strategies of fertilization at the beginning and end of the summer $(0-0,100$ $\left.0,50-50,0-100 \mathrm{~kg} \mathrm{ha}^{-1} \mathrm{~N}\right)$ were studied, respectively, with four replications. The strategy of $100 \mathrm{~kg} \mathrm{ha}^{-1}$ $\mathrm{N}$ applied at the end of the summer $(0-100)$, followed the parceling strategy at the beginning and end of the summer (50-50) favored higher rates of leaf appearance and lower values of phyllochron. Greater
\end{abstract}

\footnotetext{
${ }^{1}$ Profs. Drs. do Dept ${ }^{\circ}$ de Tecnologia Rural e Animal, Universidade Estadual do Sudoeste da Bahia, UESB, Itapetinga, BA. E-mail: fteixeira@uesb.edu.br; aureliano@pq.cnpq.br; ffsilva@pq.cnpq.br; pvnn2004@yahoo.com.br

${ }^{2}$ Prof $^{\mathrm{a}} \mathrm{Dr}^{\mathrm{a}}$ do $\mathrm{Dept}^{\mathrm{o}}$ de Estudos Básicos e Instrumentais, UESB, Itapetinga, BA. E-mail: friesdd@hotmail.com

${ }^{3}$ Pesquisadora da Comissão Executiva do Plano da Lavoura Cacaueira, CEPLAC, Itabela, BA. E-mail: claudiaprezende@hotmail. com

${ }^{4}$ Discentes de Graduação em Zootecnia, UESB, Itapetinga, BA. E-mail: sandrocotrim@yahoo.com.br; ftxzoo@yahoo.com.br

* Autor para correspondência
} 
rate of leaf elongation was observed for 0-100 strategy, resulting in 40\% increase compared to pastures that were not fertilized. However, there was no effect of fertilization strategies on stem elongation rate, registering an average of $0.28 \mathrm{~cm} \cdot \mathrm{dia}^{-1}$. There was a higher blade:stem ratio for the stratum A $(40 \mathrm{~cm}$ above the soil) in all treatments, observing higher blade:stem ratio for strategies $0-100$ and 50-50, at this stratum. There was no effect for the total number of leaves and final leaf length. However, greater stem lengths were observed in pastures with $0-100$ fertilizer strategy, followed by the 50-50 strategy. The strategy of applying $100 \mathrm{~kg} \mathrm{ha}^{-1}$ at the end of summer, followed by the strategy of $50 \mathrm{~kg} \mathrm{ha}^{-1}$ nitrogen divided at the beginning and end of summer, promote greater influence on the morphogenic and structural traits, in pastures deferred for 95 days.

Key words: Deferred grazing, morphogenesis, phyllochron, urea

\section{Introdução}

A grande extensão de área cultivada pelo gênero Brachiaria no Brasil, revelam a flexibilidade de uso, manejo e adaptação desta espécie à diversidade de condições de solos e clima. Entretanto, a quantidade de informações geradas sobre princípios ecofisiológicos de gramíneas desse gênero, ainda representa pouco (FONSECA; MARTUSCELLO; FARIA, 2006).

Segundo Fagundes et al. (2006) o sucesso na utilização de pastagem não depende apenas da disponibilidade de nutrientes ou da escolha da espécie forrageira, mas também da compreensão dos mecanismos morfofisiológicos e de sua interação com o ambiente e manejo. A combinação das variáveis morfogênicas determina as principais características estruturais da pastagem: tamanho de folha, densidade populacional de perfilhos e número de folhas vivas por perfilho (LEMAIRE; CHAPMAN, 1996). De acordo com Cecato et al. (2000), qualquer efeito sobre a taxa de alongamento foliar afetará a velocidade de emissão de folhas, bem como o surgimento de perfilhos, e consequentemente produção de matéria seca total.

Segundo Santos et al. (2009), as estratégias de manejo, além de garantir o equilíbrio entre a demanda de forragem e sua oferta aos animais, devem manter a sustentabilidade da pastagem. O diferimento de pastagem é um manejo que visa o acúmulo de forragem no final do verão para ser utilizado no período seco. Por se tratar de longos períodos de descanso, geralmente entre 70 a 150 dias, os pastos submetidos a este tipo de manejo, podem apresentar redução no número de perfilhos, consequência da crescente competição por luz entre os perfilhos. Considerando que o nitrogênio tem efeito positivo sobre o perfilhamento, estratégias de adubação nitrogenada podem ser realizadas durante o verão como forma de aumentar a produção de forragem em pastos diferidos. A aplicação de nitrogênio também tem a vantagem de estimular o perfilhamento da gramínea (FAGUNDES et al., 2006; MISTURA, 2004).

O entendimento das características morfogênicas e estruturais constitui importante ferramenta visando compreender os efeitos das estratégias de manejo utilizadas em pastos diferidos e recomendar aquelas mais eficientes, sem comprometer sua persistência pela redução do número de perfilhos. Este trabalho teve como objetivo avaliar as características morfogênicas, estruturais e a densidade populacional de perfilhos de pastos de $B$. decumbens para determinar estratégias de adubação nitrogenada, mais adequadas para o pastejo diferido por um período de 95 dias.

\section{Material e Métodos}

O experimento foi conduzido no Setor de Bovinocultura da Universidade Estadual do Sudoeste da Bahia - UESB, Campus de Itapetinga, $\mathrm{BA}$, região Sudoeste da Bahia, localizada a $15^{\circ} 18^{\prime}$ 14 " de latitude sul e $40^{\circ} 12^{\prime} 10^{\prime \prime}$ de longitude oeste e altitude de $268 \mathrm{~m}$, durante o período de novembro de 2008 a setembro de 2009. 
O clima da região é do tipo " $\mathrm{Cw}$ " mesotérmico úmido e subúmido, quente e com inverno seco, pela classificação de Köppen. O verão é quente e abrange os meses de outubro a março, enquanto o período seco é frio, sem chuvas, e inclui os meses de maio a outubro $(25 \%$ da precipitação anual). A precipitação média anual dos últimos 14 anos é de $852 \mathrm{~mm}$ e temperatura média anual de $27^{\circ} \mathrm{C}$ (Tabela 1). O solo da área experimental é um Chernossolo Argilúvio hipereutrófico, de textura franco-arenosa e com relevo levemente ondulado.

Tabela 1. Médias mensais da temperatura média diária, mínima mensal, índice pluviométrico histórico e do período experimental durante os períodos de novembro de 2008 a novembro de 2009.

\begin{tabular}{lcccc}
\hline \multicolumn{1}{c}{ Mês/Ano } & $\begin{array}{c}\text { Temperatura } \\
\text { média }\left({ }^{\circ} \mathrm{C}\right)\end{array}$ & $\begin{array}{c}\text { Temperatura mínima } \\
\left({ }^{\circ} \mathrm{C}\right)\end{array}$ & $\begin{array}{c}\text { Índice } \\
\text { pluviométrico } \\
\text { histórico }(\mathrm{mm})\end{array}$ & $\begin{array}{c}\text { Índice pluv. per. } \\
\text { experimental (mm) }\end{array}$ \\
\hline Novembro/2008 & 26,4 & 21,0 & 131,8 & 113,4 \\
Dezembro/2008 & 26,8 & 21,0 & 124,7 & 189,3 \\
Janeiro/2009 & 27,6 & 20,0 & 75,6 & 78,4 \\
Fevereiro/2009 & 28,0 & 20,0 & 82,4 & 5,6 \\
Março/2009 & 28,9 & 20,0 & 136,5 & 83,4 \\
Abril/2009 & 27,6 & 21,0 & 75,2 & 112,4 \\
Maio/2009 & 25,2 & 17,0 & 46,0 & 17,8 \\
Junho/2009 & 23,9 & 16,0 & 27,6 & 41,1 \\
Julho/2009 & 26,0 & 15,0 & 46,0 & 6,1 \\
Agosto/2009 & 25,9 & 16,0 & 33,0 & 70,4 \\
Setembro/2009 & 26,8 & 16,0 & 21,2 & 41,2 \\
Outubro/2009 & 28,5 & 18,0 & 60,4 & 145,9 \\
Novembro/2009 & 30,5 & 19,0 & 131,8 & 13,8 \\
\hline
\end{tabular}

Fonte: Elaboração dos autores.

O delineamento experimental adotado foi $\mathrm{o}$ de blocos casualizados com quatro tratamentos e quatro repetições, com exceção da variável relação lâmina:colmo, que foi adotado o esquema de parcela subdividida. Os tratamentos foram distribuídos aleatoriamente em quatro blocos (piquetes) de 441 $\mathrm{m}^{2}$, cercados com fios de arame liso eletrificado, divididos em quatro parcelas de $100 \mathrm{~m}^{2}(10 \mathrm{x} 10$ $\mathrm{m})$, descontando-se a bordadura. $\mathrm{O}$ experimento foi instalado em uma pastagem bem estabelecida de B. decumbens formada em 1993. No dia 27 de novembro de 2008 foi realizado um pastejo de uniformização, logo em seguida a marcação da área das parcelas e por fim a coleta de amostras de solos, à profundidade de $0 \mathrm{a} 20 \mathrm{~cm}$, cujos resultados da análise química foram: $\mathrm{pH}$ em água $=5,6 ; \mathrm{P}$ disponível $=2,5 \mathrm{mg} / \mathrm{dm}^{3} ; \mathrm{K}=0,3 \mathrm{cmol}_{\mathrm{c}} / \mathrm{dm}^{3} ; \mathrm{Ca}=$ 2,4 e $\mathrm{Mg}=1,9 \mathrm{cmol}_{\mathrm{c}} / \mathrm{dm}^{3} ; \mathrm{Al}=0,1 \mathrm{e} \mathrm{H}^{+}=2,6 \mathrm{cmol}_{\mathrm{c}} /$ $\mathrm{dm}^{3} ; \mathrm{V}=62 \%$; e $\mathrm{CTC}=7,3 \mathrm{cmol}_{\mathrm{c}} / \mathrm{dm}^{3}$. Considerando os valores de saturação de bases da análise dos solos, não houve necessidade de correção da acidez. A aplicação de $\mathrm{K}$ também não foi necessária, com base nos resultados da análise de solos que podem ser considerados muito bons (RIBEIRO; GUIMARÃES; ALVAREZ V, 1999). Embora os teores de P serem considerados baixos (RIBEIRO; GUIMARÃES; ALVAREZ V, 1999), optou-se por não fazer adubação fosfatada, considerando que a prática do diferimento normalmente é utilizada em sistemas de baixo nível tecnológico. Geralmente estes sistemas de produção não fazem nenhum uso de fertilizantes em pastagens, portanto o objetivo deste 
estudo foi avaliar apenas a adubação nitrogenada no primeiro ano de aplicação.

Foram estudadas as estratégias de aplicação de nitrogênio no início e no final do verão: T1- sem adubação $(0,0)$, T2- $100 \mathrm{~kg} / \mathrm{ha}$ de $\mathrm{N}$ no início do verão (100-0), T3- parcelamento de $50 \mathrm{~kg} / \mathrm{ha}$ de N no início e $50 \mathrm{~kg} / \mathrm{ha}$ de $\mathrm{N}$ no final do verão (50$50)$, e T4- $100 \mathrm{~kg} /$ ha de $\mathrm{N}$ no final do verão (0100). No caso da variável lâmina:colmo, também foram estudadas as combinações entre as mesmas estratégias de aplicação do nitrogênio, casualizadas as parcelas, e as alturas de colheita de forragem: estrato A- acima de $40 \mathrm{~cm}$; B- 20-40 cm; e C- 0-20 $\mathrm{cm}$ do solo, casualizadas as subparcelas. A adubação nitrogenada na forma de uréia foi aplicada no final de novembro de 2008, para o tratamento 100-0 e a primeira dose do tratamento 50-50, caracterizando o início do verão e em meados de março de 2009 foram adubados os tratamentos 0-100 e a segunda dose do tratamento 50-50, caracterizando o final do verão.

Durante o período de novembro de 2008 a março de 2009, os piquetes (blocos) foram manejados sob lotação intermitente com período de descanso de 28 dias, utilizando novilhas Holandês/Zebu com peso corporal médio de $150 \mathrm{~kg}$, adotando-se a técnica de mob-grazing, com grupos de novilhas para desfolhações rápidas, simulando um cenário de pastejo, que assegurou, entre os tratamentos, uma altura no pós-pastejo em torno de $15 \mathrm{~cm}$. Antes da vedação, os pastos foram utilizados intensivamente, rebaixados para $10 \mathrm{~cm}$ de altura e após a última parcela da adubação nitrogenada, 21 de março, os pastos foram vedados a entrada dos animais até o dia 24 de junho de 2009, perfazendo um período de 95 dias.

Para a avaliação das características morfogênicas foram identificados aleatoriamente seis perfilhos por parcela com fitas de cores diferentes. Cada repetição foi constituída pelo valor médio dos seis perfilhos de cada parcela. Foi definido como data de aparecimento foliar o dia em que se observou a exposição do ápice foliar e definida como folha expandida o dia de aparecimento da lígula. O comprimento da lâmina emergente foi medido do seu ápice até a lígula da última folha expandida. As observações foram feitas duas vezes por semana.

Foram calculadas as seguintes variáveis morfogênicas: taxa de aparecimento de folha, filocrono, taxa de alongamento de folha e taxa de alongamento de colmo. A taxa de aparecimento de folhas (folhas/dia) foi calculada pela divisão do número de folhas totalmente expandidas (lígula exposta) surgidas por perfilho, pelo número de dias envolvidos. Filocrono corresponde ao inverso da taxa de aparecimento de folhas, e significa o intervalo de tempo, em dias, para aparecimento de duas folhas sucessivas. A taxa de alongamento foliar $\left(\mathrm{cm} \cdot \mathrm{dia}^{-1}\right)$ foi obtida dividindo comprimento total final de lâminas foliares, pelo número de dias até o aparecimento da lígula. A taxa de alongamento de colmo foi obtida dividindo a diferença entre o comprimento final e o comprimento inicial do colmo, pelo intervalo entre corte.

As características estruturais estudadas foram: relação lâmina:colmo, número de folhas totais, comprimento final de folha e comprimento do colmo, obtidas nos dias do corte. Para determinação da relação lâmina:colmo, as amostras foram colhidas de forma estratificada de 20 em $20 \mathrm{~cm}$ partindo-se do topo do dossel, em três estratos verticais $\mathrm{A}, \mathrm{B}$ e $\mathrm{C}$, com auxílio de um equipamento denominado estratificador, com dimensões de 70 $\mathrm{cm}$ x $70 \mathrm{~cm}\left(0,49 \mathrm{~m}^{2}\right)$ e $140 \mathrm{~cm}$ de altura. Para guiar a altura do corte, um quadrado de ferro foi acoplado ao estratificador, sendo sustentado por ganchos de metal (HACK et al., 2007). As amostras colhidas foram acondicionadas em sacos plásticos e no laboratório foram pesados, homogeneizadas e separadas em lâmina foliar, colmo (bainha e colmo) e forragem morta, considerando a proporção de cada componente morfológico e após a separação, os componentes foram acondicionados em saco de papel, pesados e secos em estufa de $105^{\circ} \mathrm{C}$ por 24 horas para determinação da matéria seca definitiva. 
A relação lâmina:colmo foi calculada como sendo o quociente entre a matéria seca de folhas e a matéria seca de colmos.

Os dados foram avaliados por meio de análise de variância, num modelo matemático com os efeitos fixos de tratamento e bloco, aplicando o teste Duncan a $5 \%$ de probabilidade, além dos coeficientes de determinação. No caso da relação lâmina:colmo foram analisados os efeitos de tratamento, estrato, bloco e a interação entre esses fatores, que foi desdobrada, ou não, de acordo com a sua significância. Os efeitos das parcelas e subparcelas, para esta característica, foram avaliados pela aplicação do teste Tukey a 5\% de probabilidade, por se tratar de dados qualitativos, também foram observados os coeficientes de determinação. Para realizar as análises estatísticas foi utilizado o Sistema de Análises Estatísticas e Genéticas - SAEG (RIBEIRO JÚNIOR, 2001).

\section{Resultados e Discussão}

Foram verificados efeitos $(\mathrm{P}>0,05)$ sobre a estratégia de aplicação de nitrogênio no início e no final do verão $\left(0-0,100-0,50-50,0-100 \mathrm{~kg} \cdot \mathrm{ha}^{-1}\right.$ de $\mathrm{N}$ ), para as características morfogênicas, taxa de aparecimento de folha (TApF), filocrono e taxa de alongamento de folha (TAlF). No entanto, para taxa de alongamento de colmo (TAlC), não foi encontrado efeito $(\mathrm{P}>0,05)$ em relação as estratégias de aplicação de nitrogênio avaliadas.

A adubação nitrogenada aumentou $(\mathrm{P}<0,05)$ a TApF, em relação ao tratamento controle (0-0), em 23, 17 e 13\% para as estratégias de aplicação de $\mathrm{N}$ no final do verão (0-100), parcelados no início e final do verão (50-50) e aplicados no início do verão (100-0), respectivamente (Figura 2). Os resultados deste trabalho evidenciam a importância do $\mathrm{N}$ no aumento da produção de novas células contribuindo para o aparecimento de novas folhas, que segundo Duru e Ducrocq (2000), o papel do suprimento deste elemento é o resultado da combinação de uma série de fatores tais como idade ao corte, alongamento foliar e temperatura, que agem simultaneamente. Desta maneira, à medida que as folhas se alongam, ocorre alteração do padrão de aparecimento de lâminas foliares, em função da modificação de tempo gasto pela folha, da sua iniciação no meristema até seu aparecimento acima do colmo formado pelas folhas mais velhas.

Figura 1. Taxa de aparecimento de folhas em pastos de $B$. decumbens diferidos, sob quatro estratégias de aplicação de nitrogênio.

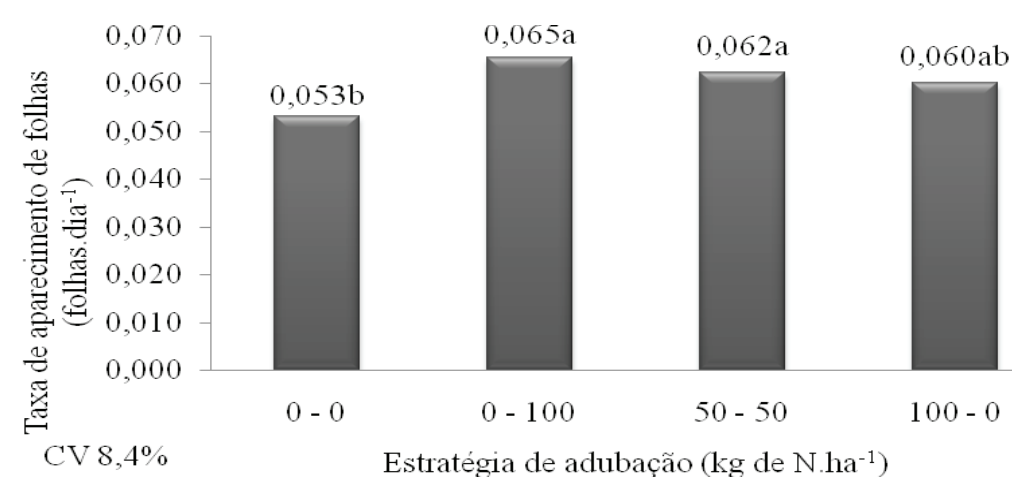

Fonte: Elaboração dos autores.

O maior valor de TApF encontrado neste estudo foi 0,065 folhas/perfilho.dia ${ }^{-1}$, próximo aos 0,067 folhas.perfilho.dia ${ }^{-1}$ relatados por Marcelino et al. (2006) avaliaram frequência de desfolhação com 
9 folhas e 56 dias de intervalo de corte em capim marandu. Esses resultados podem ser explicados pela maior duração do intervalo entre cortes, característica do manejo de pastos diferidos, que no caso deste trabalho foi de 95 dias, refletindo na TApF. Provavelmente, o aumento da competição por fotoassimilados com o aumento da idade da planta, podem ter sido mobilizados para o desenvolvimento de novas estruturas que surgem no meristema apical (OLIVEIRA et al., 2000). Estes processos de formação e desenvolvimento de folhas, de acordo com Gomide e Gomide (2000) são fundamentais para o crescimento vegetal, dado o papel das folhas na fotossíntese, que é ponto de partida para a formação de novos tecidos.

Foram verificados menores $(\mathrm{P}<0,05)$ valores de filocrono para os pastos submetidos às estratégias de adubação com aplicação de $\mathrm{N}$ no final do verão, 0-100 e 50-50, registrando redução de 3,5 e 2,7 dias em relação ao tratamento controle, respectivamente (Figura 3). Inversamente aos resultados da TApF
(Figura 2), a redução do filocrono, ou seja, intervalo de tempo para aparecimento de duas folhas sucessivas, observados nestes tratamentos, indicam que a adubação nitrogenada próximo ao período de vedação aumentou a velocidade de rebrota das plantas. Considerando o momento da adubação, mês de março, seguido do mês de abril, as condições ambientais (Tabela 1) ainda eram favoráveis, ou seja, coincidiu estrategicamente com as últimas chuvas e temperaturas elevadas no momento da adubação. Este fato certamente potencializou os efeitos do nitrogênio sobre a redução do filocrono, pelo maior intervalo de colheita, característico dos pastos diferidos e da época de vedação que coincide normalmente com o outono/inverno. Segundo Oliveira et al. (2000), à medida que avança o estádio de desenvolvimento da planta, após passar por uma fase de intenso aparecimento de folhas e perfilhos, observa-se contínuo alongamento do colmo, resultando em aumento do filocrono de folhas individuais.

Figura 2. Filocrono em pastos de $B$. decumbens diferidos, sob quatro estratégias de adubação nitrogenada no início e no final do verão.

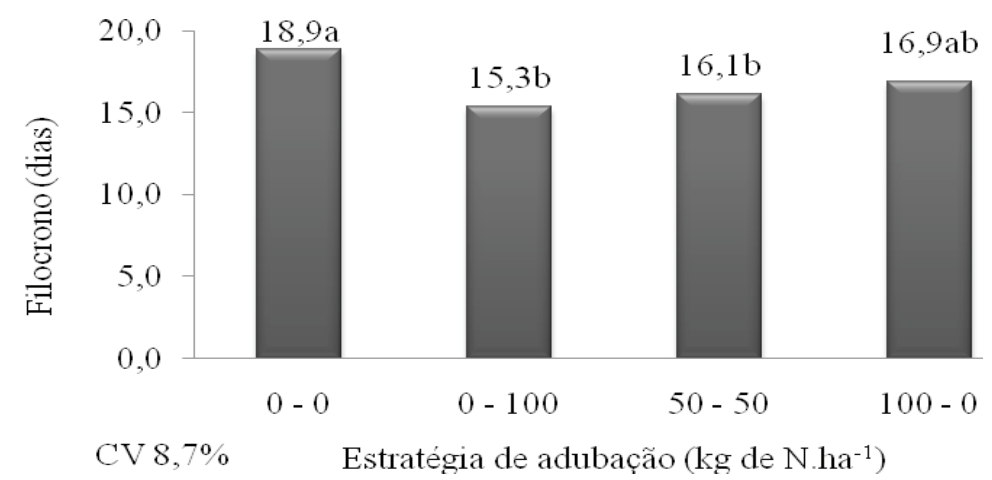

Fonte: Elaboração dos autores.

Embora constatado os efeitos do nitrogênio sobre a redução do filocrono, os valores relatados neste estudo podem ser considerados elevados, quando comparados aos resultados de Silva et al. (2009), que verificaram menor valor de filocrono para $B$. decumbens em relação a $B$. brizantha, além de uma redução estimada de 6,0 dias.folha $^{-1}$ com aplicação de 160 mg.dm ${ }^{-3}$ de nitrogênio para o B. decumbens. Alexandrino et al. (2004), trabalhando com $B$. brizantha submetida a três doses de nitrogênio em casa de vegetação, constataram que a medida que se elevou o suprimento de N, 0, 20 e $40 \mathrm{mg}$ de nitrogênio. $\mathrm{dm}^{-3}$.semana, diminuíram o filocrono em 12,$2 ; 8,47$ e 6,99 dias/folha, respectivamente. 
A estratégia de adubação com $100 \mathrm{~kg} \cdot \mathrm{ha}^{-1}$ de nitrogênio, no final do verão (0-100) proporcionou maior $(\mathrm{P}<0,05) \mathrm{TAlF}$, com aumento de $40 \%$ em relação aos pastos que não foram adubados (Figura 4). Pode-se inferir que a maior dose de nitrogênio aplicado próximo ao período de vedação, aliado as condições favoráveis nesse momento, favoreceu o maior alongamento das folhas, em contrapartida as aplicações em períodos mais distantes do momento do diferimento (100-0) e até mesmo a estratégia de parcelamento no início e final do verão (50-50), não foram capazes de contribuir para o alongamento foliar. Estes resultados podem ser explicados pelo rápido efeito do $\mathrm{N}$ no metabolismo das plantas e da saída deste nutriente do sistema por meio da colheita realizada com o pastejo das novilhas antes da vedação. Além disso, a grande mobilidade deste elemento no solo e a utilização de uréia como fertilizante, certamente potencializou essas perdas.

Figura 3. Taxa de alongamento foliar em pastos de B. decumbens diferidos, sob quatro estratégias de adubação nitrogenada no início e no final do verão.

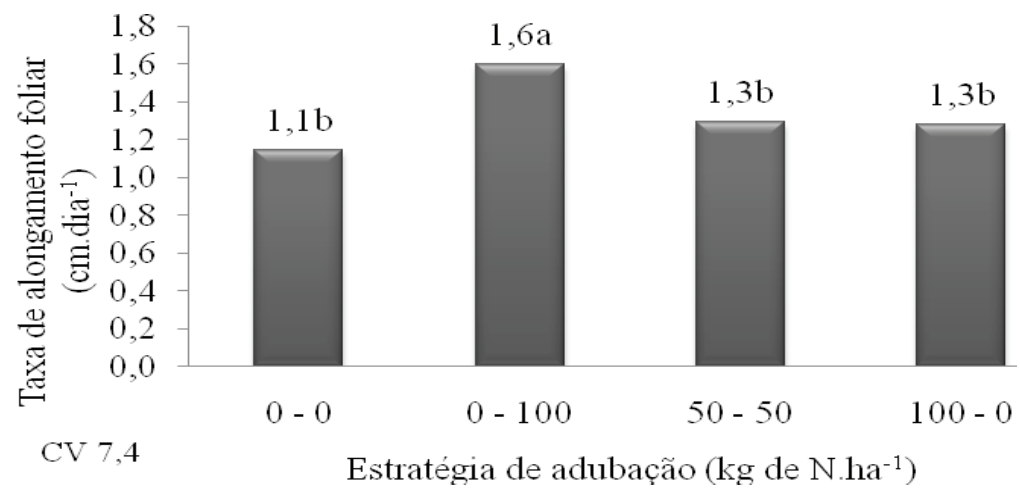

Fonte: Elaboração dos autores.

A adubação nitrogenada afeta o alongamento foliar, considerando que o maior acúmulo de $\mathrm{N}$ encontra-se na zona de divisão celular, responsável pela resposta positiva na TAlF com o uso da adubação nitrogenada (GASTAL; NELSON, 1994). Silva et al. (2009) constatou que a B. decumbens respondeu de forma positiva a adubação nitrogenada até a dose de $182 \mathrm{mg} \cdot \mathrm{dm}^{-3}$ de nitrogênio, com TAlF de $1,7 \mathrm{~cm} /$ folha.dia $^{-1}$, resultados próximos aos encontrados neste estudo para estratégia de aplicação de $100 \mathrm{~kg} \cdot \mathrm{ha}^{-1}$ de nitrogênio, no final do verão (0-100). Garcez Neto et al. (2002) também constataram aumentos médios de $133 \%$ na TAIF em Panicum maximum cv. Mombaça quando as doses de nitrogênio variaram de 0 a $200 \mathrm{mg} \cdot \mathrm{dm}^{-3}$, ratificando o significativo papel deste nutriente no comportamento desta variável. Vilela et al.
(2013) avaliando características estruturais em Brachiaria brizantha $\mathrm{cv}$. Piata submetido a períodos de diferimento (65, 85 e 105 dias) e alturas iniciais de adiamento (20, 30 e $40 \mathrm{~cm})$, verificaram que o comprimento do caule de perfilhos basais vegetativas aumentou com o aumento dos períodos de diferimento, constatando pouco efeito das alturas de diferimento iniciais sobre as características estruturais dos perfilhos.

Não houve efeito das estratégias de adubação sobre a taxa de alongamento de colmo $(\mathrm{P}<0,05)$, registrando-se média de $0,28 \mathrm{~cm} \cdot \mathrm{dia}^{-1}$. Entretanto, pode-se considerar maior influência das condições ambientais favoráveis no início do período de vedação (outono), pois a medida que a planta se desenvolveu e os fatores como pluviosidade e temperatura se tornaram limitantes, certamente reduziu esta média. 
Marcelino et al. (2006), trabalhando com capimmarandu submetido a intensidades e freqüências de desfolhação, verificaram as taxas de alongamento de colmo foram maiores nos tratamentos com menores frequências de corte, relatando $0,28 \mathrm{~cm} \cdot \mathrm{dia}^{-1}$ para frequência de desfolhação com $20 \mathrm{~cm}$, semelhante ao valor médio encontrado neste estudo.

Em função do período de diferimento do pasto, normalmente mais longo que o manejo tradicional, uma das limitações verificadas neste tipo de manejo é o acentuado alongamento do colmo, que geralmente apresenta maior taxa de alongamento no início da vedação, quando as condições climáticas são favoráveis, diminuindo a medida que essas condições se tornam limitantes. Lopes (2006) estudando as características morfofisiológicas do capim mombaça submetido a regimes de desfolhação, constatou menor taxa de alongamento de colmos com o menor período de rebrotação, devido a maior competição por luz no interior do dossel forrageiro. Segundo Santos et al. (2004), em gramíneas tropicais, o manejo deve favorecer o controle do florescimento, reduzindo o alongamento do colmo e, conseqüentemente, aumentando o valor nutritivo da forragem ofertada aos animais.

Foram verificados efeitos $(\mathrm{P}>0,05)$ sobre a estratégia de aplicação de nitrogênio no início e no final do verão $\left(0-0,100-0,50-50,0-100 \mathrm{~kg} \cdot \mathrm{ha}^{-1}\right.$ de $\mathrm{N})$ para as características estruturais, relação lâmina:colmo, número de folhas e o comprimento final de colmo (CFC). Não houve efeito $(\mathrm{P}>0,05)$ sobre o comprimento final de folha (CFF). Segundo Teixeira et al. (2013), a adubação nitrogenada no final do verão favorece a densidade populacional de perfilhos, além de assegurar altas taxas de natalidade de perfilhos durante a estação de crescimento em pastos de Urochroa decumbens diferidos por 95 dias, o que poderia compensar em quantidade de folhas por ha.
Para a relação lâmina:colmo, houve efeito entre os estratos de corte e da estratégia de adubação, além da interação estrato de corte $\times$ estratégia de adubação $(\mathrm{P}<0,05)$. Decompondo o efeito no estrato, houve maior $(\mathrm{P}<0,05)$ relação lâmina:colmo para o estrato A em todos os tratamentos, como já era esperado, pois neste estrato, geralmente, é onde ocorre maior concentração de folhas. Por outro lado, a relação lâmina:colmo no estrato $\mathrm{C}$ foi a mais baixa devido maior concentração de colmos, especialmente por se tratar de pastos diferidos por um período de 95 dias. No estrato $\mathrm{A}$ foi observado maior $(\mathrm{P}<0,05)$ relação lâmina:colmo para as estratégias de $100 \mathrm{~kg} \cdot \mathrm{ha}^{-1} \mathrm{de}$ $\mathrm{N}$, aplicados no final do verão (0-100) e parcelados no início e final do verão (50-50), provavelmente, o nitrogênio aplicado próximo ao período de vedação proporcionou maior concentração de folhas neste estrato (Tabela 2).

Moreira et al. (2009), trabalhando com $B$. decumbens adubado com nitrogênio, encontraram relação lâmina:colmo para planta inteira de 0,68 em março do primeiro ano e valores entre 0,44 e 0,62 no segundo ano,considerando. Os autores consideraram esses valores baixos, em razão do manejo do pastejo adotado, ou seja, lotação contínua e altura do pasto mantida em $20 \mathrm{~cm}$ que, provavelmente, influenciou a seletividade de pastejo pelos animais, que por sua vez preferem lâminas foliares. De acordo com Alexandrino et al. (2004), a folha é um importante componente para a produção de massa seca da planta, destacando que, além de interceptar boa parte da energia luminosa, e representar parte substancial do tecido fotossintético ativo, garante a produção de fotoassimilados, e constitui-se em material de alto valor nutritivo. Os resultados obtidos neste estudo, em diferentes estratos verticais evidenciaram de forma mais detalhada a relação lâmina:colmo no dossel da planta, facilitando a interpretação do manejo mais adequado para pastos diferidos. 
Tabela 2. Relação folha colmo ${ }^{1}$ de pastos de $B$. decumbens diferidos, sob quatro estratégias de adubação nitrogenada em três estratos verticais

\begin{tabular}{ccccc}
\hline \multirow{2}{*}{ Estrato1 } & \multicolumn{4}{c}{ Adubação $^{2}$} \\
\cline { 2 - 5 } & $0-0$ & $0-100$ & $50-50$ & $100-0$ \\
\hline $\mathrm{A}$ & $5,52 \mathrm{Ac}$ & $7,46 \mathrm{Aa}$ & $7,31 \mathrm{Aa}$ & $6,26 \mathrm{Ab}$ \\
$\mathrm{B}$ & $0,71 \mathrm{Ba}$ & $1,38 \mathrm{Ba}$ & $1,26 \mathrm{Ba}$ & $0,81 \mathrm{Ba}$ \\
$\mathrm{C}$ & $0,19 \mathrm{Ca}$ & $0,33 \mathrm{Ca}$ & $0,44 \mathrm{Ca}$ & $0,57 \mathrm{Ba}$ \\
\hline
\end{tabular}

CV $13,4 \%$

Médias seguidas de letras minúsculas distintas na linha e de letras maiúsculas distintas na coluna diferem pelo teste Tukey (P<0,05); ${ }^{1}$ Estrato A: acima de $40 \mathrm{~cm}$, estrato B: $20-40 \mathrm{~cm}$ e estrato C: 0-20 cm do solo; $2 \mathrm{~kg} \cdot \mathrm{ha}^{-1}$ de N, aplicado no início e/ou no final do verão $\left(0-0,100-0,50-50,0-100 \mathrm{~kg} \cdot \mathrm{ha}^{-1} \mathrm{de} \mathrm{N}\right)$.

Fonte: Elaboração dos autores.

Com relação ao número de folhas totais, embora não observado efeito $(\mathrm{P}<0,05)$ entre os pastos que receberam adubação nitrogenada, os valores foram maiores $(\mathrm{P}<0,05)$ quando comparados aos pastos que não foram adubados (Figura 5). Silva et al. (2009), comparando B. decumbens com $B$. brizantha constataram maior número total de folhas por perfilho para decumbens (média de 8,8 folhas) em relação a $B$. brizantha (7,5 folhas), também encontraram influência da adubação nitrogenada $(\mathrm{P}<0,05)$ no número total de folhas por perfilho e a dose que proporcionou maior NTF/perfilho (9,3 lâminas foliares) foi de $157 \mathrm{mg} /$ $\mathrm{dm}^{3}$ de N. Alexandrino et al. (2004), trabalhando com B. brizantha adubado com nitrogênio, verificaram elevação do número de folhas totais com o aumento do tempo de rebrota e das doses de N.

Figura 4. Número de folhas vivas por perfilhos em pastos de $B$. decumbens diferidos, sob quatro estratégias de adubação nitrogenada no início e no final do verão.

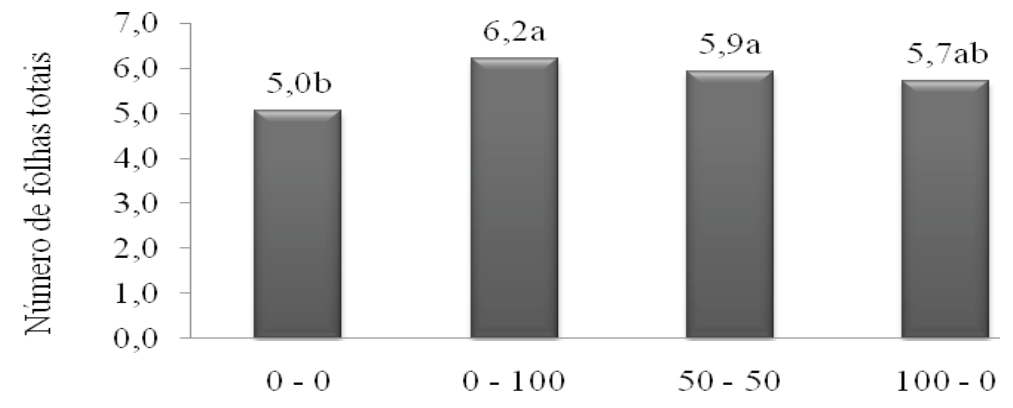

CV 8,4 Estratégia de adubação (kg de N.ha $\left.{ }^{-1}\right)$

Fonte: Elaboração dos autores.

Segundo Nascimento Júnior et al. (2002), o número de folhas num perfilho representa importante referência ao potencial de perfilhamento, pois cada gema axilar associada a uma folha gerada pode, potencialmente, gerar um novo perfilho e, portanto alterar as características estruturais da forragem.
Não foi verificado efeito $(\mathrm{P}<0,05)$ do comprimento final da folhas para as estratégias estudadas, destacando-se média de $15,7 \mathrm{~cm}$ por folha. Fagundes et al. (2006), encontraram aumentos do CFF da $B$. decumbens em resposta a adubação nitrogenada, no entanto, o CFF 13,2 
$\mathrm{cm}$ no outono, foi inferior ao valor médio do CFF encontrado neste estudo na mesma estação, o que provavelmente pode ser atribuído a estratégia de aproveitamento das condições favoráveis, final do verão, no momento da vedação do pasto. De acordo com Fagundes et al. (2006) as mudanças na estrutura e composição morfológica da pastagem, decorrentes do número de folhas verdes por perfilho e do tamanho final da folha, determinam a quantidade máxima de tecido foliar verde que um perfilho acumula, associada ao número de perfilhos por área, contribui para o índice de área foliar. Esta variável é importante para a eficiência de absorção luminosa, a capacidade fotossintética do relvado e, conseqüentemente, para a produtividade da pastagem (LEMAIRE, 1997).
Maiores comprimentos de colmos $(\mathrm{P}<0,05)$ foram observados nos pastos adubados com 100 kg.ha-1 de $\mathrm{N}$, cuja estratégia foi a aplicação no final do verão (0-100) e parcelada no início e final do verão (50-50) (Figura 6). O comprimento de colmo foi em média 30 e 14\% maior, para as estratégias 0-100 e 50-50 kg.ha-1 de $\mathrm{N}$, quando comparados com os pastos que não foram adubados. Embora a adubação nitrogenada, estrategicamente, aplicada próximo ao período de vedação contribua significativamente para o aumento na produção de matéria seca e valor nutritivo, por outro lado, o incremento no comprimento do colmo aponta para a formação de um arranjo espacial da estrutura de dossel, inclusive com o tombamento das plantas, que poderia dificultar a seletividade dos animais no momento do pastejo.

Figura 5. Comprimento final do colmo em pastos de $B$. decumbens diferidos, sob quatro estratégias de adubação nitrogenada no início e no final do verão.

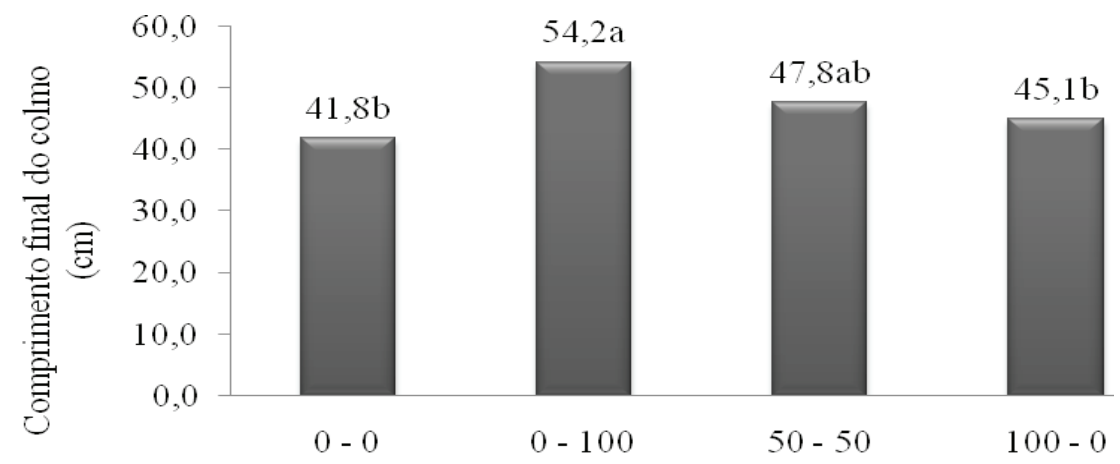

CV 9,2\% Estratégia de adubação (kg de N.ha ${ }^{-1}$ )

Fonte: Elaboração dos autores.

O controle do alongamento do colmo é um grande desafio a ser solucionado pelo manejo, particularmente, em pastos diferidos, pois o período de descanso, geralmente, é longo. Segundo Cândido et al. (2005) o período de descanso mais curto foi o único a exercer algum controle sobre o alongamento do colmo, em estudos com capim mombaça. Segundo Herling, Luz e Anchão (2005), o conhecimento da estrutura da pastagem e sua relação com o meio são fundamentais para definir o período de descanso mais adequado da planta forrageira. Para tanto, o desafio seria ajustar o tempo de diferimento do pasto, a época e a quantidade de adubo nitrogenado que interagem com a morfogênese e as características estruturais da $B$. decumbens para determinar não apenas a produtividade e valor nutritivo dos pastos, mas principalmente, uma estrutura de dossel acessível aos ruminantes em pastejo. 


\section{Conclusões}

A adubação nitrogenada no final do verão favorece as características morfogênicas e estruturais de pastos de $B$. decumbens diferidos por 95 dias. Além de aumentar a produção de matéria seca, também evita a degradação do solo, impacto da chuva e exposição ao sol.

\section{Referências}

ALEXANDRINO, E.; NASCIMENTO JÚNIOR, D.; MOSQUIM, P. R.; REGAZZI, A. J.; ROCHA, F. C. Características morfogênicas e estruturais na rebrotação da Brachiaria brizantha cv. Marandú submetida a três doses de nitrogênio. Revista Brasileira de Zootecnia, Viçosa, MG, v. 33, n. 6, p. 1372-1379, 2004.

CÂNDIDO, M. J. D.; GOMIDE, C. A. M.; ALEXANDRINO, E.; GOMIDE, J. A.; PEREIRA, W. E. Morfofisiologia do dossel de Panicum maximum cv. Mombaça sob lotação intermitente com três períodos de descanso. Revista Brasileira de Zootecnia, Viçosa, MG, v. 34, n. 2, p. 406-415, 2005.

CECATO, U.; MACHADO, A. O.; MARTINS, E. N.; PEREIRA, L. A. F.; BARBOSA, M. A. A. F.; SANTOS, G. T. Avaliação da produção e de algumas características de rebrota de cultivares e acessos de Panicum maximum Jacq. sob duas alturas de corte. Revista Brasileira de Zootecnia, Viçosa, MG, v. 29, n. 3, p. 660-668, 2000.

DURU, M.; DUCROCQ, H. Growth and senescence of the successive leaves on a Cocksfoot tiller. Effect of nitrogen and cutting regime. Annals of Botany, London, v. 85, n. 1, p. 635-643, 2000.

FAGUNDES, J. L.; FONSECA, D. M.; MISTURA, C.; MORAIS, R. V.; VITOR, C. M. T.; GOMIDE, J. A.; NASCIMENTO JUNIOR, D.; CASAGRANDE, D. R.; COSTA, L. T. Características morfogênicas e estruturais do capim braquiária em pastagem adubada com nitrogênio avaliada nas quatro estações do ano. Revista Brasileira de Zootecnia, Viçosa, MG, v. 35, n. 1, p. 21-29, 2006.

FONSECA, D. M.; MARTUSCELLO, J. A.; FARIA, D. J. G. Adubação em gramíneas do gênero Brachiaria: mitos e realidades. In: SIMPÓSIO SOBRE MANEJO ESTRATÉGICO DA PASTAGEM, 3., 2004, Viçosa. Anais... Viçosa: Departamento de Zootecnia/UFV, 2006, p. 153-182.
GARCEZ NETO, A. F.; NASCIMENTO JUNIOR, D.; REGAZZI, A. J.; FONSECA, D. M.; MOSQUIM, P. R.; GOBBI, K. F. Respostas morfogênicas e estruturais de Panicum maximum cv. Mombaça sob diferentes níveis de adubação nitrogenada e alturas de corte. Revista Brasileira de Zootecnia, Viçosa, MG, v. 31, n. 5, p. 18901900, 2002.

GASTAL, F.; NELSON, C. J. Nitrogen use whitin the growing leaf leaf of tall fescue. Plant Physiology, Illinois, v. 105, n. 1, p. 191-197, 1994.

GOMIDE, C. A. M.; GOMIDE, J. A. Morfogênese de cultivares de Panicum maximum Jacq. Revista Brasileira de Zootecnia, Viçosa, MG, v. 29, n. 2, p. 341348, 2000.

HACK, E. C.; BONA FILHO, A.; MORAES, A.; CARVALHO, P. C. F.; MARTINICHEN, D.; PEREIRA, T. N. Características estruturais e produção de leite em pastos de capim-mombaça (Panicum maximum Jacq.) submetidos a diferentes alturas de pastejo. Ciência Rural, Santa Maria, v. 37, n. 1, p. 218-222, 2007.

HERLING, V. R.; LUZ, P. H. C.; ANCHÃO, P. P. O. Manejo do pasto com vistas a maximizar a produção de ruminantes. In: VOLUMOSOS NA PRODUÇÃO DE RUMINANTES, 2005, Jaboticabal. Anais... Jaboticabal: Funep, 2005. p. 125-158.

LEMAIRE, G. The physiology of grass growth under grazing: Tissue turnover. In: SIMPÓSIO INTERNACIONAL SOBRE PRODUÇÃO ANIMAL EM PASTEJO, 1997, Viçosa, MG. Anais... Viçosa, MG: Universidade Federal de Viçosa, 1997. p. 117-144.

LEMAIRE, G.; CHAPMAN, D. Tissue flows in grazed plant communities. In: HODGSON, J.; ILLIUS, A. $\mathrm{W}$. The ecology and management of grazing systems. Wallingford: CAB International, 1996. p. 3-36.

LOPES, B. A. Características morfogênicas e acúmulo de forragem em capim-mombaça submetido a regimes de desfolhação. 2006. Tese (Doutorado em Zootecnia) Universidade Federal de Viçosa, Viçosa, MG.

MARCELINO, K. R. A.; NASCIMENTO JUNIOR, D.; SILVA, S. C. da; EUCLIDES, V. P. B.; FONSECA, D. M. Características morfogênicas e estruturais e produção de forragem do capim-marandú submetido a intensidades e freqüências de desfolhação. Revista Brasileira de Zootecnia, Viçosa, MG, v. 35, n. 6, p. 2243-2252, 2006.

MISTURA, C. Adubação nitrogenada e irrigação em pastagem de capim-elefante. 2004. Tese (Doutorado em Zootecnia) - Universidade Federal de Viçosa, Viçosa, MG. 
MOREIRA, L. M.; MARTUSCELLO, J. A.; FONSECA, D. M.; MISTURA, C.; MORAIS, R. V.; RIBEIRO JÚNIOR, J. I. Perfilhamento, acúmulo de forragem e composição bromatológica do capim braquiária adubado com nitrogênio. Revista Brasileira de Zootecnia, Viçosa, MG, v. 38, n. 9, p. 1675-1684, 2009.

NASCIMENTO JÚNIOR, D.; GARCEZ NETO, A. F.; BARBOSA, R. A.; ANDRADE, C. M. S. Fundamentos para o manejo de pastagens: evolução e atualidade. In: SIMPÓSIO SOBRE MANEJO ESTRATÉGICO DA PASTAGEM, 1., Viçosa, 2002. Anais... Viçosa: UFV, 2002. p. 149-196.

OLIVEIRA, M. A.; PEREIRA, O. G.; HUAMAN, C. A. M.; GARCIA, R.; GOMIDE, J. A.; CECON, P. R.; SILVEIRA, P. R. Características morfogênicas e estruturais do capim-bermuda "Tifton 85" (Cynodon ssp.) em diferentes idades de rebrota. Revista Brasileira de Zootecnia, Viçosa, MG, v. 26, n. 9, p. 1939-1948, 2000. Suplemento 1.

RIBEIRO JUNIOR, J. I. Análises estatísticas no SAEG: sistema para análises estatísticas. Viçosa, MG: UFV, $2001.301 \mathrm{p}$.

RIBEIRO, A. C.; GUIMARÃES, P. T. G.; ALVAREZ V., V. H. (Ed.). Recomendações para uso de corretivos e fertilizantes em Minas Gerais: $5^{\text {a }}$ aproximação. Viçosa, MG: CFSEMG/UFV, 1999. p. 13-20.
SANTOS, E. D. G.; PAULINO, M. F.; QUEIROZ, D. S.; FONSECA, D. M.; VALADARES FILHO, S. C.; LANA, R. P. Avaliação de pastagem diferida de Brachiaria decumbens Stapf. 2. Disponibilidade de forragem e desempenho animal durante a seca. Revista Brasileira de Zootecnia, Viçosa, MG, v. 33, n. 1, p. 214-224, 2004.

SANTOS, M. E. R.; FONSECA, D. M.; BALBINO, E. M.; MONNERAT, J. P. I. S.; SILVA, S. P. Caracterização dos perfilhos em pastos de capim braquiária diferidos e adubados com nitrogênio. Revista Brasileira de Zootecnia, Viçosa, MG, v. 38, n. 4, p. 643-649, 2009.

SILVA, C. C. F.; BONOMO, P.; PIRES, A. J. V.; MARANHÃO, C. M. A.; PATÊS, N. M. S.; SANTOS, L. C. Características morfogênicas e estruturais de duas espécies de braquiária adubadas com diferentes doses de nitrogênio. Revista Brasileira de Zootecnia, Viçosa, MG, v. 38, n. 4, p. 657-661, 2009.

TEIXEIRA, F. A.; BONOMO, P.; PIRES, A. J. V.; SILVA, F. F.; ABREU FILHO, G.; VIANA, P. T. Tiller population density in deferred Urochroa decumbens pasture and strategies for nitrogen fertilization. Acta Scientiarum. Animal Sciences, Maringá, v. 35, n. 1, p. 79-84, 2013.

VILELA, H. H.; SOUSA, B. M. L.; SANTOS, M. E. R.; SANTOS, A. L.; SILVA, N. A. M.; NASCIMENTO JÚNIOR, D. Characterization of tillers of piata palisade grass deferred in the fall with varying heights and deferment periods. Acta Scientiarum. Animal Sciences, Maringá, v. 35, n. 1, p. 21-27, 2013. 